\section{The Chemistry of Sustainable Supply Chains}

\section{June 2012, Toronto, Ontario, Ganada}

This workshop on the Chemistry of Sustainable Supply Chains, organized by the UUPAC Committee on Chemistry and Industry $(\mathrm{COCl})$, will explore how chemistry-based industries are contributing to sustainable development in the various supply chains in the Great Lakes Region of North America. To be held 1 June 2012 in Toronto, Ontario, Canada, this workshop is the fourth in the $\mathrm{COCl}$ series previously held in Marl, Germany, Kawasaki, Japan, and Kuwait.

This workshop will focus on the Great Lakes region where many chemical companies and their customers and suppliers are situated. Its aim is to improve communication among chemical industries, chemical societies/IUPAC members or NAOs, and $\mathrm{COCl}$. Although IUPAC occupies a unique and highly esteemed position at the center of the world of chemistry, better communication and understanding is needed. It is desirable for IUPAC to strengthen its relationship with chemical industries and absorb more suggestions from them for future activities.

The format of the workshop will

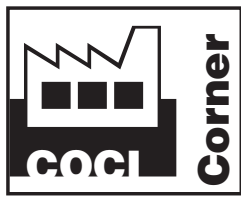
allow $\mathrm{COCl}$ to update key stakeholders on IUPAC activities, such as the safety training program, and to listen to their concerns and ideas, especially input regarding Rio+20. Finding desirable methods of interaction between industry and IUPAC will be an important outcome of the meeting.

This workshop is planned as part of IUPAC project 2011-053-1-022. Chemical companies, from small to medium enterprises to global players, are invited to take part and to support the workshop.

For more information or to suggest topics and speakers please contact Task Group Chair Bernard West <bernard.west@sympatico.ca>, COCl Chair Michael Droescher <m.droescher@t-online.de>, or COCl Member Carolyn Ribes <cribes@dow.com>.

wiil www.iupac.org/web/ins/2011-053-1-022

\section{Space Research}

\section{4-22 July 2012, Mysore, India}

The 39th COSPAR Scientific Assembly will take place 14-22 July 2012 at Narayana Murthy Centre of Excellence (Infosys Training Centre), Mysore, Karnataka, India. The assembly will offer 120 meetings covering the fields of COSPAR Scientific Commissions (SC) and panels. Following is a sampling:

- $\quad$ SC A: The Earth's Surface, Meteorology and Climate

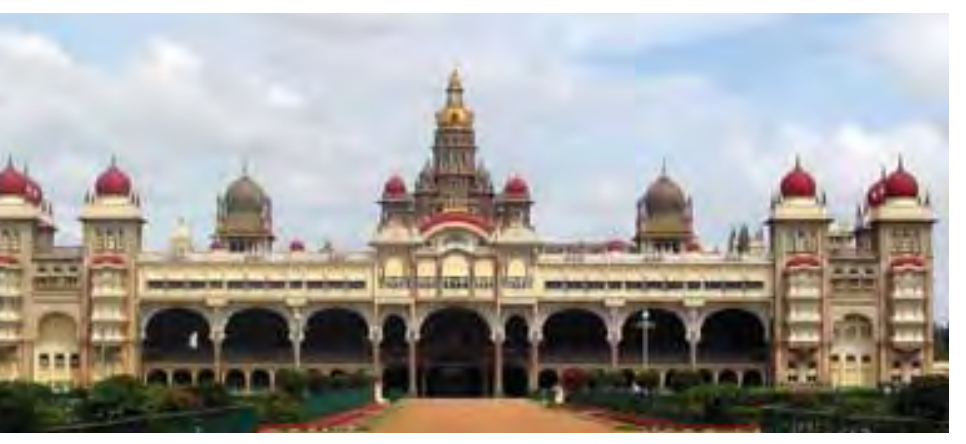

Mysore Palace.
- $\quad$ SC B: The Earth-Moon System, Planets, and Small Bodies of the Solar System

- $\quad$ SC C: The Upper Atmospheres of the Earth and Planets Including Reference Atmospheres

- SC D: Space Plasmas in the Solar System, Including Planetary Magnetospheres

- $\quad$ SC E: Research in Astrophysics from Space

- SC F: Life Sciences as Related to Space

- SC G: Materials Sciences in Space

- SC H: Fundamental Physics in Space

- Panel on Satellite Dynamics

- Panel on Scientific Ballooning

- Panel on Planetary Protection

- Panel on Capacity Building

- Panel on Education

- Panel on Exploration

The abstract deadline is 10 February 2012. For more information contact the COSPAR Secretariat <cospar@cosparhq.cnes.fr>.

\section{www.cospar2012india.org}

